\title{
Ischemic retinopathy associated with Crohn's disease
}

This article was published in the following Dove Press journal:

International Medical Case Reports Journal

25 July 2016

Number of times this article has been viewed

\author{
Rubens Camargo Siqueira ${ }^{1,2}$ \\ Roberto Luiz Kaiser Junior ${ }^{2}$ \\ Lilian Piron Ruiz ${ }^{2}$ \\ Milton Arthur Ruiz ${ }^{2}$ \\ 'Department of Ophthalmology, \\ Otorhinolaryngology and Head and \\ Neck Surgery, School of Medicine \\ of Ribeirão Preto, University of \\ Sao Paulo, Ribeirão Preto, Sao \\ Paulo, Brazil; '2Department of Bone \\ Marrow Transplantation, Beneficencia \\ Portuguesa Hospital, Sao José do Rio \\ Preto, Sao Paulo, Brazil
}

Correspondence: Rubens C Siqueira Department of Advanced Treatment of Retinal Diseases, Rubens Siqueira Research Center, Rua Saldanha Marinho 2815 Sala 42, Sao José do Rio Preto, Sao Paulo, Brazil

Tel +55 I7 32345858

Fax +55 1732140896

Email rubenssiqueira@terra.com.br
Purpose: To report a case of a patient with ischemic retinopathy associated with Crohn's disease. Case report: This report presents a case of a 28-year-old female patient with Crohn's disease and sudden decrease of visual acuity in the right eye. Fluorescein angiography, optical coherence tomography, and multifocal electroretinography confirmed the clinical features of ischemic retinopathy. After systemic corticosteroid treatment, the patient developed epiretinal membrane without significant improvement in visual acuity.

Discussion: The patient presented with ischemic retinopathy associated with Crohn's disease with deficiency of central visual acuity. Periodic examination by a retina specialist is recommended for patients being treated for Crohn's disease.

Keywords: Crohn, ischemic retinopathy, epiretinal membrane, OCT, ERG

\section{Introduction}

Crohn's disease (CD) is a regional enteritis that affects the terminal ileum, but has the potential of involving any segment of the gastrointestinal tract of the patient.

The etiology of $\mathrm{CD}$ is unknown, but several proven risk factors exist such as family history, smoking, oral contraceptives, diet, and ethnicity. The combination of risk factors, and aberrant autoimmune response in the intestinal mucosa with endothelial dysfunction lead to digestive tract malfunctioning. The current treatment is not ideal. Therapy generally involves steroids and antitumor necrosis factor alpha blockers but about one-third of patients fail to respond (primary nonresponders) and $10 \%$ of patients do not tolerate or are primary nonresponders to all drugs used. One-third of responders to antitumor necrosis factor treatment show transient loss of response (secondary nonresponders). Severe cases may require partial resection of a segment of bowel, possibly total colectomy with the placement of stoma bags for feces when the disease affects the rectum.

Ophthalmic manifestations have been reported to occur in up to $12 \%$ of patients with $\mathrm{CD}$ and most of them include iritis, uveitis, episcleritis, and conjunctivitis. However, posterior segment manifestations are very rare, occurring in less than $1 \%$ of patients. ${ }^{1-4}$

\section{Case report}

A 28-year-old female was admitted because of sudden decrease of visual acuity in the right eye. She had been diagnosed as suffering from $\mathrm{CD}$. She had undergone resection of a $40 \mathrm{~cm}$ segment of bowel due to stenosis. She was refractory to treatment using 


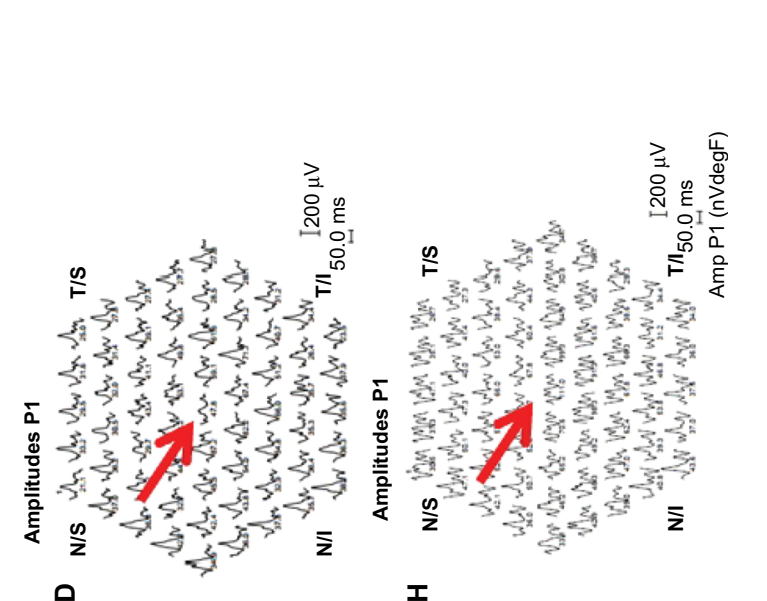

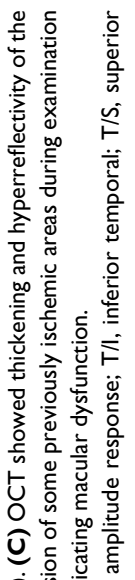

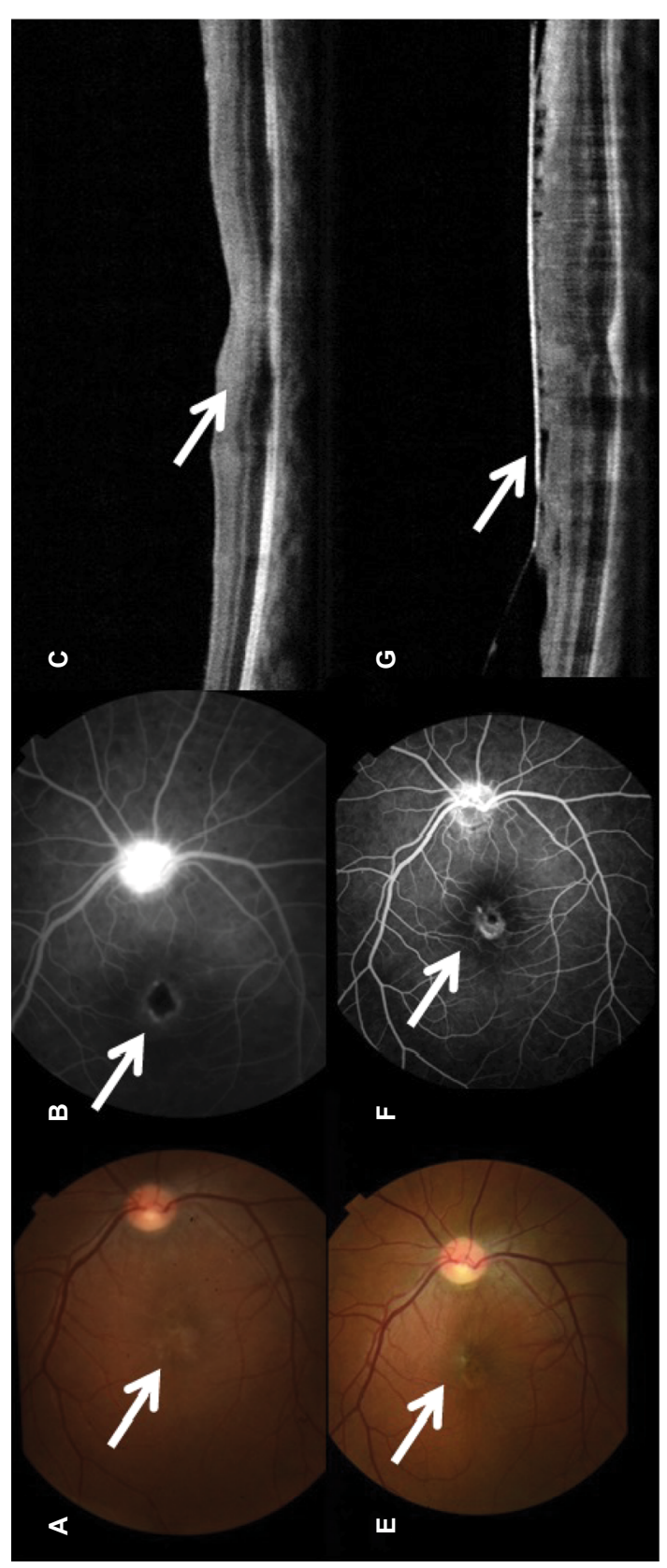

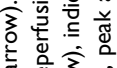

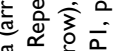
离艺毞

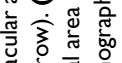
है 递 $\stackrel{0}{5}$ on 은 응

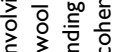

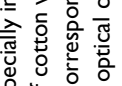
के ठ पे

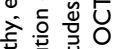

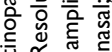
는 흐는

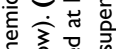

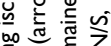

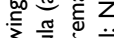

ن่

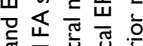
它密要逜气

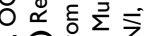
伦包完全 券

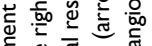

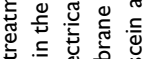
ऊ $\frac{0}{0}$ है

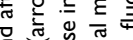

당



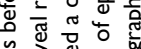

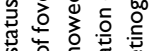

तु 0 ज

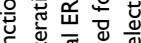

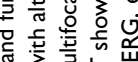

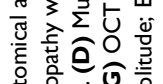

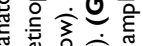

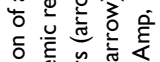

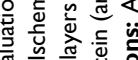

㟧㐫焉




corticosteroids, azathioprine, infliximab, and adalimumab. The patient suffered repeated episodes of abdominal pain, mucous bloody diarrhea, weight loss, and depression.

At presentation, she underwent a complete ophthalmological examination. Visual acuity was 20/400 in the right eye. Examination of the anterior segment was normal and the lens was clear. Bilateral intraocular pressure was $13 \mathrm{mmHg}$. Ophthalmoscopic examination with mydriasis showed severe ischemic retinopathy in the right eye (Figure 1A). Retinal fluorescein angiography showed ischemic retinopathy, especially involving the macular area (Figure 1B). Optical coherence tomography showed thickening and hyperreflectivity of the inner retinal layers, including the nerve fiber and ganglion cell layers owing to ischemia of the superficial capillary plexus (Figure 1C) and multifocal electroretinography showed a decrease of electrical responses representing central macula (Figure 1D).

These features suggested the clinical diagnosis of ischemic retinopathy secondary to $\mathrm{CD}$.

We prescribed prednisone $60 \mathrm{mg}$ daily and scheduled new follow-up tests.

Visual acuity showed a slight improvement (20/150), with resolution of cotton wool spots (Figure 1E) and reperfusion of some previously ischemic areas during examination with fluorescein (Figure 1F). After 3 months, we observed the formation of an epiretinal membrane (Figure $1 \mathrm{G}$ ), but without significant macular edema or bleeding. Multifocal electroretinography remained at low amplitudes meaning macular dysfunction (Figure $1 \mathrm{H}$ ).

\section{Discussion}

We present a case of CD complicated by ischemic retinopathy with irreversible damage of central visual acuity.

Several factors are associated with an increased risk of ocular manifestations. Patients with colitis and ileocolitis tend to have a higher risk of ocular involvement compared to those with ileitis alone. ${ }^{5}$ Presence of other organ involvement also increases the risk. ${ }^{5,6}$ Particularly, in patients with CD and arthralgia, the risk of ocular involvement increases to $33 \%$.

Falavarjani et $\mathrm{al}^{7}$ described a 9-year-old male with biopsyproven $\mathrm{CD}$ who developed a cilioretinal artery-sparing central retinal artery occlusion. Trojet et $\mathrm{al}^{8}$ reported a 55-year-old male with $\mathrm{CD}$ with associated retinal vasculitis involving the veins, papillitis, cystoid macular edema.

The pathophysiology of the extraintestinal manifestations of CD is not well understood, but it is most likely mediated by the inflammatory nature of the disease. Several proposed mechanisms include circulating antigen-antibody complexes or autoantibody production against cellular antigens shared by the colon and extraintestinal organs. ${ }^{9}$ Inflammation causing damage to mucosa of the intestinal epithelium may allow proteins or microorganisms to pass through the intestinal barrier and cause a reactive lymphoid tissue response. This, in turn, results in antibody production or antigen-antibody complexes that circulate in the body and cause systemic inflammation. This immune response to a colonic antigen may explain why ocular manifestations may occur more commonly with colitis and ileocolitis than with small bowel involvement alone. Microbial pathogens, through molecular mimicry, may also contribute to the pathogenesis, though this is still being investigated. Genetic factors may also play a role in ocular manifestations. Patients with extraintestinal manifestations of CD have a higher prevalence of HLA-B27 type leukocytes than the regular. ${ }^{10}$

Ocular complications are categorized as primary, secondary, and coincidental. ${ }^{11}$ Primary complications are temporally associated with $\mathrm{CD}$ exacerbations and tend to resolve with systemic treatment of the intestinal inflammation. These include keratopathy, episcleritis, and scleritis. Secondary complications arise from primary complications. Examples include cataract formation due to treatment with corticosteroids, scleromalacia due to scleritis, and dry eye due to hypovitaminosis A following gut resection. Coincidental complications occur commonly in the general population and cannot be correlated to inflammatory bowel disease alone. These include conjunctivitis, recurrent corneal erosions, and corneal ulcer. ${ }^{11-13}$

Ocular involvement does not always coincide with active intestinal flare. However, in instances when it does, as is typical of episcleritis, this can be used as an indicator of disease activity, indicating the need for more aggressive management. $^{12}$

In this case report, the pathogenesis of ischemia in retinal vasculitis is not clear but is suggested to be either thrombotic or obliterative, secondary to the infiltration of inflammatory cells. Based on histological studies, vascular changes in uveitis are characterized by perivascular infiltration of lymphocytes, which results in perivasculitis rather than true vasculitis of the vessel wall. ${ }^{14}$ Cell-mediated immunity also plays a role in the pathology of retinal vasculitis, with CD4+ T cells documented within and around the retinal vessels. Thrombotic vascular changes can occur due to local endothelial injury or increased prothrombin activity as observed in Behçet's disease. ${ }^{14,15}$ The retina has a uniquely high metabolic demand for oxygen that is normally met by a highly efficient vascular supply. Insufficiency of the retinal 
circulation causes neuroretinal dysfunction and degeneration. Focal retinal ischemia results in selective damage to specific subpopulations of retinal neurons and can result in cellular death by apoptosis or necrosis, with dysfunction and degeneration of the inner retina and eventually visual loss. Retinal vascular obstruction can also promote the production of vascular endothelial growth factor, which increases vascular permeability and results in macular edema and induced neovascularization. ${ }^{15,16}$

Treatment of ocular manifestations ranges from controlling the underlying intestinal inflammation, topical steroids, systemic nonsteroidal anti-inflammatory drugs, systemic steroids, and immunosuppressant and biological agents. In refractory or severe cases, treatment with monoclonal antibodies has shown promise.

Periodic examination by a retina specialist is recommended for patients being treated for CD.

\section{Acknowledgments}

This study was approved by ethics committee of the Beneficencia Portuguesa Hospital in Sao José do Rio Preto, Sao Paulo, Brazil. The patient signed the consent form in the Bone Marrow Transplant Unit of the Beneficencia Portuguesa Hospital of São José do Rio Preto which is accredited by the National Transplant System of the Ministry of Health of Brazil. The consent forms are reviewed and approved by the ethics committee of the Beneficencia Portuguesa Hospital which is accredited by the National Committee of Ethics and Research in Brazil.

\section{Disclosure}

The authors report no conflicts of interest in this work.

\section{References}

1. Abraham C, Cho JH. Inflammatory bowel disease. $N$ Engl $J$ Med. 2009;361(21):2066-2078

2. Kalla R, Ventham N, Satsangi J, Arnott I. Crohn's disease-clinical review. BMJ. 2014;349:g6670.

3. Taylor SR, McCluskey P, Lightman S. The ocular manifestations of inflammatory bowel disease. Curr Opin Ophthalmol. 2006;17(6): 538-544.

4. Zippi M, Corrado C, Pica R, et al. Extraintestinal manifestations in a large series of Italian inflammatory bowel disease patients. World $J$ Gastroenterol. 2014;20(46):17463-17467.

5. Salmon JF, Wright JP, Murray AD. Ocular inflammation in Crohn's disease. Ophthalmology. 1991;98:480-484.

6. Felekis T, Katsanos K, Kitsanou M, et al. Spectrum and frequency of ophthalmologic manifestations in patients with inflammatory bowel disease: a prospective single-center study. Inflamm Bowel Dis. 2009;15(1):29-34.

7. Falavarjani KG, Parvaresh MM, Shahraki K, Nekoozadeh S, Amirfarhangi A. Central retinal artery occlusion in Crohn disease. J AAPOS. 2012;16(4):392-393.

8. Trojet S, Mazlout H, Hamdouni M, et al. Retinal vasculitis in Crohn's disease: a case report. J Fr Ophtalmol. 2010;33(1):54.e1-55.

9. Das KM. Relationship of extraintestinal involvements in inflammatory bowel disease: new insights into autoimmune pathogenesis. Dig Dis Sci. 1999;44(1):1-13.

10. Mallas EG, Mackintosh P, Asquith P, Cooke WT. Histocompatibility antigens in inflammatory bowel disease; their clinical significance and their association with arthropathy with special reference to HLA B27 (W27). Gut. 1976;17(11):906-910.

11. Akpek EK, Thorne JE, Qazi FA, Do DV, Jabs DA. Evaluation of patients with scleritis for systemic disease. Ophthalmology. 2004;111(3): 501-506.

12. Knox DL, Schachat AP, Mustonen E. Primary, secondary and coincidental ocular complications of Crohn's disease. Ophthalmology. 1984;91(2):163-173.

13. Mady R, Grover W, Butrus S. Ocular complications of inflammatory bowel disease. Scientific World J. 2015;2015:438402.

14. Hughes EH, Dick AD. The pathology and pathogenesis of retinal vasculitis. Neuropathol Appl Neurobiol. 2003;29(4):325-340.

15. Talat $L$, Lightman $S$, Tomkins-Netzer O. Ischemic retinal vasculitis and its management. J Ophthalmol. 2014;2014:197675.

16. Palmer HE, Stanford MR, Sanders MD, Graham EM. Visual outcome of patients with idiopathic ischaemic and non-ischaemic retinal vasculitis. Eye (Lond). 1996;10(3):343-348.
International Medical Case Reports Journal

\section{Publish your work in this journal}

The International Medical Case Reports Journal is an international, peer-reviewed open-access journal publishing original case reports from all medical specialties. Previously unpublished medical posters are also accepted relating to any area of clinical or preclinical science. Submissions should not normally exceed 2,000 words or

\section{Dovepress}

4 published pages including figures, diagrams and references. The manuscript management system is completely online and includes a very quick and fair peer-review system, which is all easy to use. Visit http://www.dovepress.com/testimonials.php to read real quotes from published authors. 